\title{
A prospective randomized study of ACL-reconstructions using bone-patellar tendon-bone grafts fixed with bioabsorbable or metal interference screws
}

\author{
Jon Olav Drogset • Lene Granrud Straume • \\ Ingrid Bjørkmo • Gunnar Myhr
}

Received: 18 April 2009/Accepted: 30 November 2010/Published online: 14 January 2011

(C) The Author(s) 2011. This article is published with open access at Springerlink.com

\begin{abstract} easier revision surgery. absorbable screws was also analyzed. patients with bioabsorbable screws.

\author{
J. O. Drogset \\ Norwegian University of Science and Technology, \\ Trondheim, Norway \\ L. G. Straume $(\bowtie) \cdot$ I. Bjørkmo \\ Norwegian University of Science and Technology, \\ Trondheim, Norway \\ e-mail: Jon.O.Drogset@ntnu.no \\ G. Myhr \\ Unilabs Røntgen, Trondheim, Norway
}

Trondheim University Hospital,
\end{abstract}

Introduction Bioabsorbable screws are, at the expense of metal screws, increasingly used as fixation device in ACLreconstructions. The possible advantages with bioabsorbable screws are better postoperative MRI evaluations and

Purpose The aim of this study was to compare the clinical outcome after ACL-reconstructions with BPTB-grafts fixed with metal interference screws or bioabsorbable screws 7 years postoperatively. The resorption of the bio-

Methods Between 2000 and 2001, 41 patients with ACL deficient knees were randomized for the use of BPTB-graft fixed with either metal interference screws or bioabsorbable poly-L-lactic acid screws. This is a 7-year follow-up with clinical examinations of both groups and, MRI of the

Results The clinical and functional results were satisfactory in both groups. There were no significant differences between the groups in any parameter measured, except for better Pivot shift results in the bioscrew group $(P=0.04)$. The MRI evaluation showed degradation of the bioscrews. A residual screw tract which appeared threaded was seen in the tibia in 11 of the 16 patients. There was no sign of bony ingrowth in the previous screw site in the tibia in any of the patients.

Conclusion The potential advantages of using PLLAscrews compared to metal screws are not sufficient to warrant the routine use of PLLA-screws in ACLreconstructions.

Level of evidence $\mathrm{I}$.

Keywords Anterior cruciate ligament (ACL) reconstructions · Bone-patellar tendon-graft . Bioabsorbable interference screw · Poly-L-lactic acid (PLLA) · Magnetic resonance imaging (MRI) · Resorption

\section{Introduction}

Rupture of the anterior cruciate ligament (ACL) is a common knee injury, and subsequently functional instability is often noted [1, 2, 4, 17, 29]. ACL-reconstruction with bone-patellar-tendon-bone (BPTB) autograft used to be the method of choice. This graft is found to give good long-term clinical results [13, 15, 37]. Metallic interference screws have been the standard graft fixation method in ACL-reconstructions with BPTB-grafts. These screws give a solid fixation and are well tolerated by the body [11, 19]. However, there are some potential disadvantages. The presence of metallic interference screws can complicate revision surgery and may require a second operation for removal. MRI may also be more difficult to interpret [27, 28]. For these reasons, bioabsorbable interference screws have been developed.

Bioabsorbable cannulated interference screws were introduced for arthroscopic ACL-reconstruction in the early 1990s [6, 7]. Polylactic acid is widely used as the 
main component in bioabsorbable screws. Different bioabsorbable screws are available, e.g. polyglycolic acid (PGA), polylactic acid (PLA), poly-L-lactic acid (PLLA), poly-D-lactic acid (PDLLA), and polyparadioxanone (PDS).

If the bioabsorbable screw is to be an alternative to metal screws, it has to show adequate fixation and remain secure for at least 6-8 weeks until the bone block has been incorporated and biological fixation is achieved [6, 26, 28]. With regard to revision surgery, it is also important that the screw eventually will degrade, and that new bone formation will take place at the site of the implant. Studies have revealed that PLA screw resorption can take several years $[3,7,8,34,44]$.

Several studies comparing metal screws and bioabsorbable interference screw have been performed. They support the conclusion that bioabsorbable screws are a reasonable alternative to metal interference screws $[9,16$, $18,19,25,31,35,38]$. Bioabsorbable screws are also found to provide as good fixation as metal screws [18, 21].

The aim of this study was to evaluate the clinical outcome 7 years following ACL-reconstruction with bone-patellar-tendon-bone (BPTB) grafts in patients with bioabsorbable PLLA interference screws and metal interference screws. The postoperative resorption and the bony integration of the bioabsorbable screws evaluated by MRI were analyzed. The hypotheses were that there is no difference in the clinical outcome between the groups and that the bioabsorbable interference screws are fully resorbed.

\section{Materials and methods}

This study is a follow-up of patients included and randomized between 2000 and 2001 [14]. A total of 41 patients were included in the study, 22 women and 19 men. The included patients had isolated ACL ruptures or ACLruptures with additional minor meniscal lesions and/or minor cartilage lesions (Outerbridge grade I and II). After a diagnostic arthroscopy, the patients were randomized according to the envelope method for the use of either metal interference screws (Linvatec ${ }^{\circledR}$, Largo, FL, USA) or the BioScrews (Linvatec ${ }^{\circledR}$, Largo, FL, USA). All ACLs were reconstructed with a BPTB graft. A total of 21 patients were randomized to reconstruction with bioabsorbable screws and 20 patients to metal screws. There were no statistically significant differences between the two groups in any measured parameter preoperatively [14].

The mean follow-up time was 7.5 years $(6.6-8.3)$. Of the 41 patients, $34(83 \%)$ were examined (17 in metal screw group (M), 17 in BioScrew group (B)). One patient did not want to participate (B), one patient did not want to travel (M), and three of the patients were impossible to get in touch with (one in B, two in M). Two patients in the BioScrew group were excluded because of graft failure and revision ACL-surgery during the follow-up period. Three patients were partially excluded from clinical comparisons due to a rupture of the contralateral ACL during follow-up (two in $\mathrm{B}$, one in $\mathrm{M}$ ). These patients were only included in the evaluation of the subjective function, clinical assessment of swelling and Lysholm score. The 31 remaining patients (16 in $\mathrm{M}, 15$ in $\mathrm{B}$ ) underwent all the clinical evaluations. A total of 16 of the 17 patients in the BioScrew group available for the 7 year follow-up had an MRI examination performed. One patient was excluded because of pregnancy. The MRI was obtained at an average of 7.8 years $(7.3-8.3)$ after surgery.

The follow-up examination included Lysholm function score, Tegner activity score, Knee injury and Osteoarthritis Outcome Score (KOOS), Lachman test, Pivot-shift test, KT-1000 arthrometer examination and a clinical assessment of swelling. The patients also graded their subjective knee function as excellent, good, fair or poor.

The MRI examinations were performed on a Siemens Symphony 1.5-T MRI scanner. A dedicated knee coil was used to obtain the following image sequences: sagittal turbo spin echo (TSE), 4000/16 and coronal fat saturated TSE 2600/14-16; 4-mm slice thickness, and image matrix, $256 \times 384$. Two oblique coronal TSE 2840/14 imaging sequences with slice thickness $3 \mathrm{~mm}$ and image matrix $256 \times 384$ were added in all patients. The number of excitations was 2 for the fat saturated sequence and 1 for the others. The field of view was 15 . The echo train length was 7 for all sequences. The oblique sequences were oriented along the biological screws. All the MRI examinations were analyzed by the same radiologist as in the 2 year follow-up [12].

The integration of the bone block was considered good if no border between the bone block and the bone was visible on MRI. Osteolysis around the screws was defined as visible fluid around the screws. Widening of the tibial tunnel was estimated at a distance of $2 \mathrm{~cm}$ from the joint line.

The measurement of the screw volume preoperatively (V1) was calculated from the formula $\mathrm{V} 1=\pi r^{2} \times h$, where $r=$ radius of the screw and $h=$ length of the screw [12].

Measurements of volume of possible remnants of screws was calculated from the formula $V=\pi(1 / 2(r 1+r 2))^{2} \times h$, where $r 1=$ largest radius and $r 2=$ smallest radius.

All the surgeries were carried out at the Orthopaedic Department at St. Olav's Hospital in Trondheim by four experienced knee surgeons as described earlier. The reconstructions were done using an endoscopic technique [14]. The femoral tunnels were located at 11 o'clock in the right knee and at 1 o'clock in the left knee [14]. The femoral bone block was fixed from the inside with a cannulated PLLA or metal interference screw of $7 \times 25 \mathrm{~mm}$. The bone block in 
the tibial tunnel was fixed with an interference screw of 8 or $9 \times 25 \mathrm{~mm}$ with the knee in extension [14].

The rehabilitation program was the same in both groups and supervised by the same two physiotherapists [14].

Statistic analysis

The power analysis was primarily performed for the KT1000 measurements. A comparison of the differences between the groups was made with the Student's $t$ test for continuous variables and with the chi-square test and Fisher exact test for categorical variables. In all tests, an alpha level of 0.05 was considered significant.

\section{Results}

There was no statistically significant difference between the two groups in any of the five subscales in the KOOS score (Fig. 1), in subjective assessments of knee function (Table 1), or in reported pain during the clinical examination. The median Tegner activity score had decreased in both groups during the follow-up time from 2 to 7 years $(P<0.05)$, and there was no significant difference between the two groups at review (n.s.) (Fig. 2).

The mean Lysholm score was $90( \pm 9)$ for the metal screw group and $89( \pm 10)$ in the BioScrew group at review (n.s.). The mean Lysholm score in both groups combined was $95( \pm 5)$ at 2 years [14] and $89( \pm 9)$ at 7 years

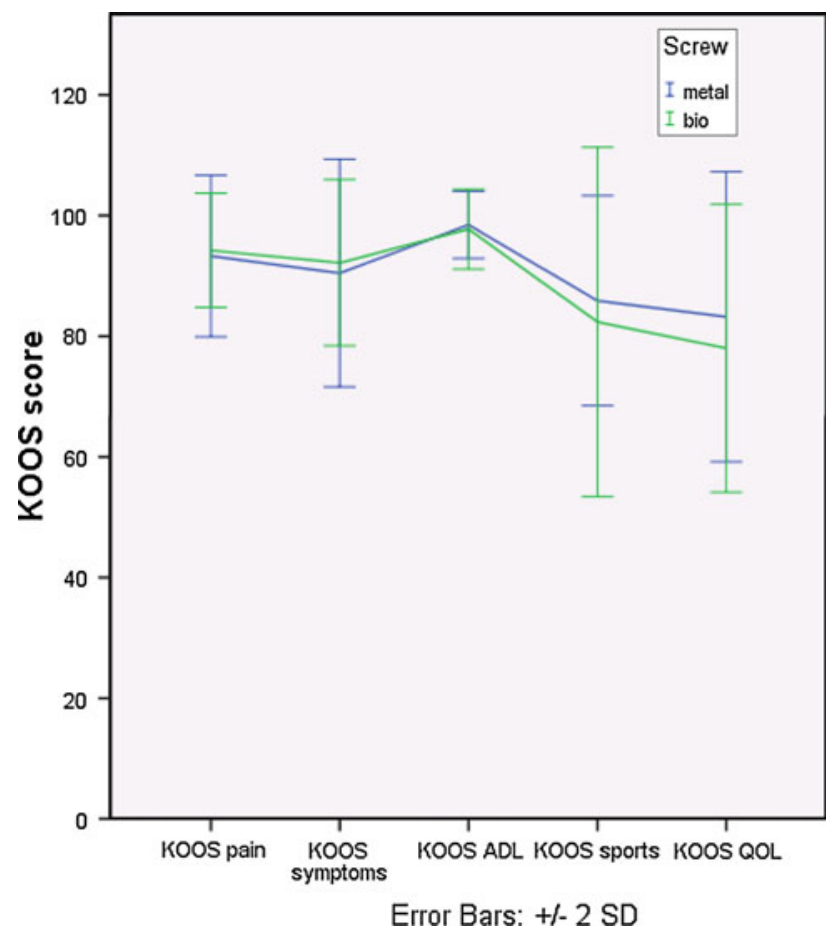

Fig. 1 Mean KOOS scores in the two groups 7 years postoperatively
$(P<0.05)$. The 7 year follow-up score, however, was higher than the mean preoperative score at $68( \pm 14)$ $(P<0.05)$. Figure 3 shows the mean Lysholm score in the two groups from preoperatively to 7 years postoperatively.

Table 1 Subjective knee function as evaluated by the patients 7 years postoperatively

\begin{tabular}{|c|c|c|c|}
\hline Subjective knee function & Metal screw & Bioscrew & $P$ \\
\hline Excellent & 7 & 5 & \\
\hline Good & 9 & 10 & \\
\hline Fair & 1 & 2 & \\
\hline Poor & 0 & 0 & \\
\hline
\end{tabular}

n.s.

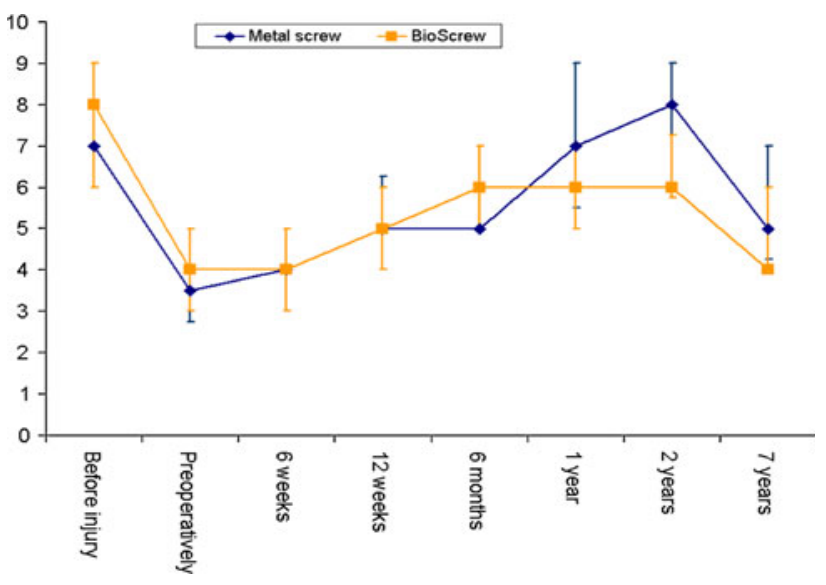

Fig. 2 Median Tegner activity score in the two groups [14]

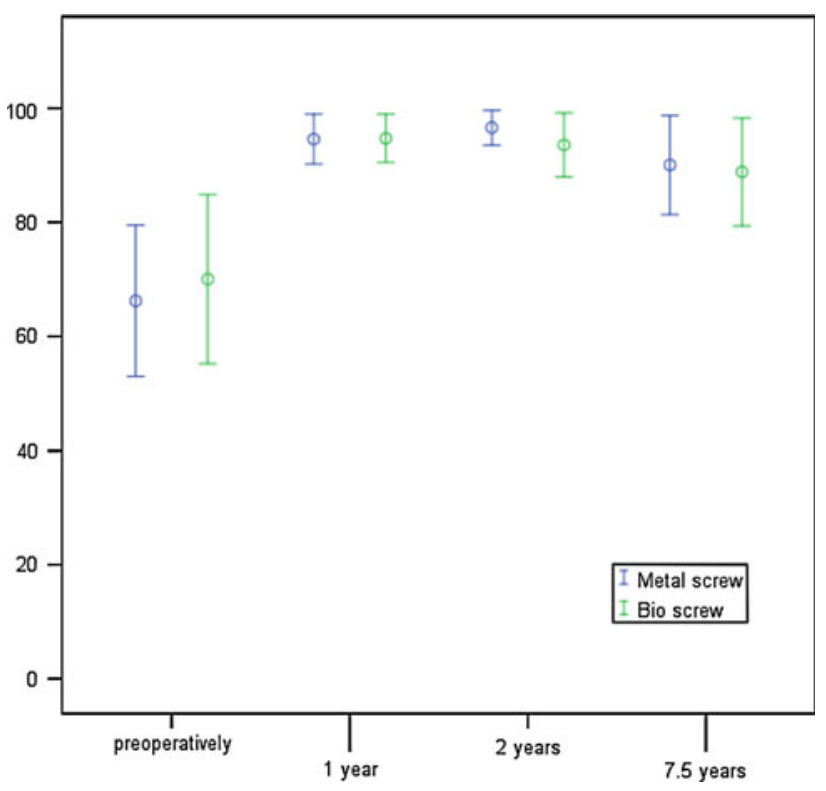

Fig. 3 Mean Lysholm functional score and SD in the two groups [14] 
None of the patients in any group had a limited ROM at the 7 years examination. Table 2 shows the Pivot shift test, Lachman test and KT-1000 measurements. The Pivot-shift test showed less laxity in the bioabsorbable group than the metal group $(P=0.04)$. Two patients had a pivot glide in the metal group and none in the BioScrew group. On the KT1000 measurements six patients in the BioScrew group had 3-5 mm increased laxity compared to 1 in the metal screw group $(P<0.05)$. By regrouping these results as stable $(<3 \mathrm{~mm})$ versus non-stable $(\geq 3 \mathrm{~mm})$, there was no statistically significant difference between the groups. Three patients in the metal group had a KT-1000 (maximum manual force) over $5 \mathrm{~mm}(8 \mathrm{~mm}, 6 \mathrm{~mm}, 6 \mathrm{~mm})$ and none in the BioScrew group (n.s.). The mean KT-1000 values were 1.8 for the metal group and 1.7 for the BioScrew group (n.s.). The corresponding values preoperatively were $4.3 \mathrm{~mm}$ and $5.5 \mathrm{~mm}$. One patient in the metal screw group and none in the BioScrew group had a Lachman test grade 2 (n.s.). None of the patients in either group had an intra articular or localised swelling of the knee at the 7 year follow-up examination.

\section{MRI}

The mean volume of the screws preoperatively was $1,088 \mathrm{~mm}^{2} \quad(962-1,256)$ for the femur screws and

Table 2 Assessment of laxity in the two groups

\begin{tabular}{llll}
\hline Grade & Metal screw & Bioscrew & $P$ \\
\hline Pivot shift test & & & \\
0 & 9 & 14 & \\
1 & 5 & 1 & \\
2 & 2 & 0 &
\end{tabular}

Lachman test

$\begin{array}{lll}0 & 8 & 6 \\ 1 & 7 & 9 \\ 2 & 1 & 0\end{array}$

KT-1000 arthrometer (max. man. force)

$\begin{array}{lrl}<3 \mathrm{~mm} & 12 & 9 \\ 3-5 \mathrm{~mm} & 1 & 6 \\ >5 \mathrm{~mm} & 3 & 0\end{array}$

n.s.

KT-1000 arthrometer (max. man. force) regrouped

$\begin{array}{rrr}<3 \mathrm{~mm} & 12 & 9 \\ \geq 3 \mathrm{~mm} & 4 & 6\end{array}$

KT-1000 arthrometer (max. man. force)

$\begin{array}{lll}\text { Mean } & 1.8 & 1.7 \\ \text { SD } & 2.9 & 2.4\end{array}$

$1,269 \mathrm{~mm}^{2}$ for the tibia screws [12]. At the 7 year follow-up we could not detect intact screws in the tibia or the femur in any of the 16 patients.

A residual screw tract which appeared threaded was seen in the tibia in 11 of the 16 patients. These tracts were surrounded by a hypointense rim and were filled with amorphous soft tissue-like material (Fig. 4a). The thickness of the threaded rim varied in these patients. The mean volume of this delineated "screw-ghost" was $406 \mathrm{~mm}^{2}$ (191-678). In five of the patients, the residual screw tract was not clearly threaded and the surrounding rim was more indistinct (Fig. 4b). There was no sign of a significant bony ingrowth in the screw sites in the tibia in any of the patients.
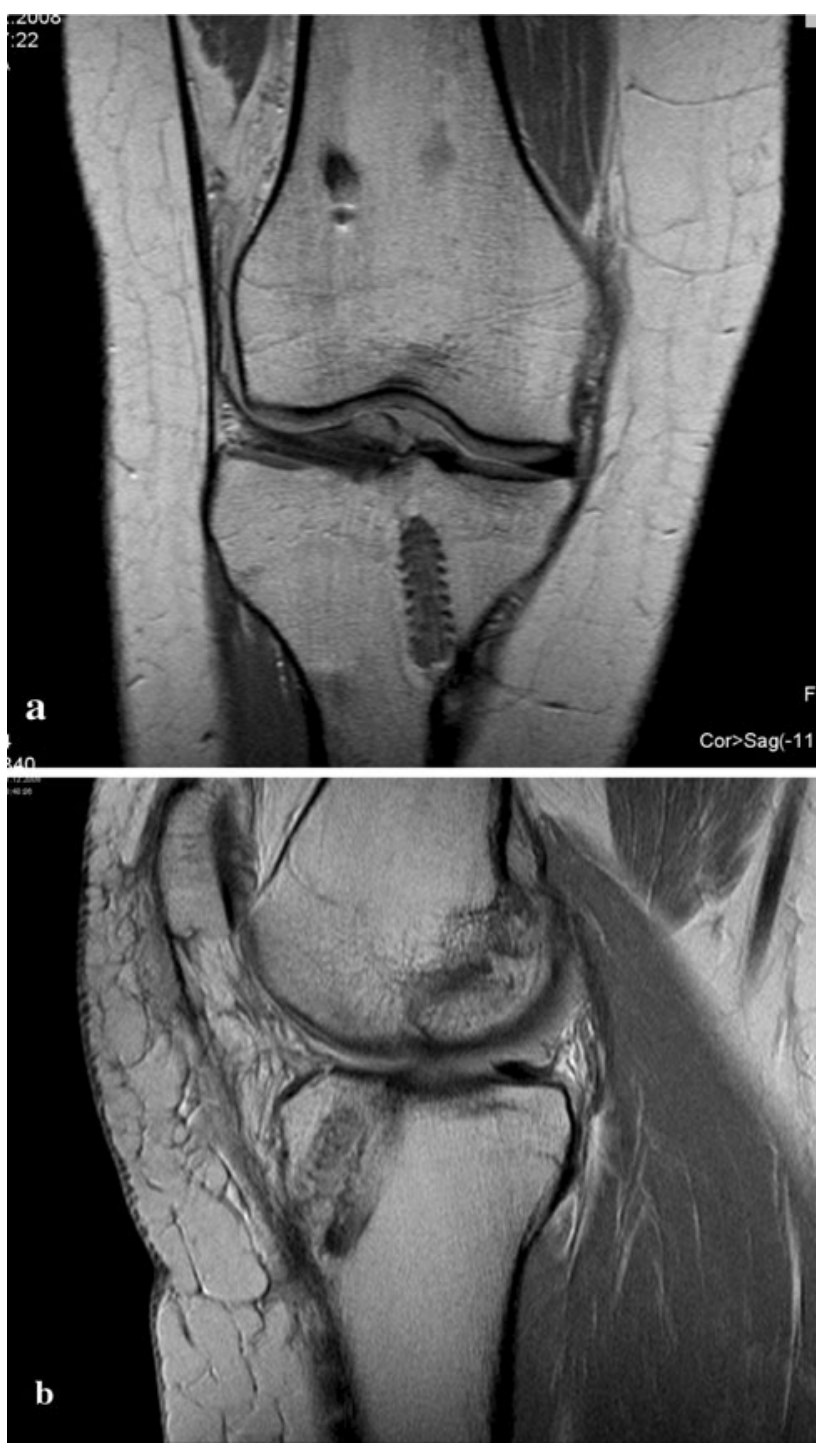

Fig. 4 Comparison of threaded tibial residual tract (a) and a not threaded, more indistinct tibial residual tract (b). Both images show reabsorbed screw 
In the femur the residual screw tracts appeared different from the tibial tracts. The tract did not appear threaded in any of the patients, and the surrounding hypointense rim was in general thinner and less distinct than the rim in the tibia. These residual tracts were also filled with a material consistent with soft tissue, and there were no signs of significant bony replacement in the screw sites (Fig. 5).

The MRI did not reveal tibial tunnel widening in any of the 16 patients, and the integration of the bone block in both the femur and the tibia was considered good in all patients. There was no change in bone plug position, visible osteolysis, inflammatory bone marrow edema or other complications in any of the patients.

\section{Discussion}

The most important finding of the present study was that the BioScrews had degraded 7 years after surgery; however, the screws were not replaced by bone. The screws used in our study were made of $100 \%$ poly-L-lactic acid, a widely used material for fixations [20]. Studies have revealed that screw resorption can take several years $[3,34$, 44].

Reports show faster degradation of other bioabsorbable fixation materials. Lajtai et al. [22] showed that bioabsorbable copolymer (85/15 D, L lactide/glycolide) screws remain intact for 4 months and disappear in 6 months. Barber et al. [5] also showed that the " $\mathrm{D}$ " isomer in a polyD-L-lactic interference fixation screw speeds the degradations process compared to the PLLA.

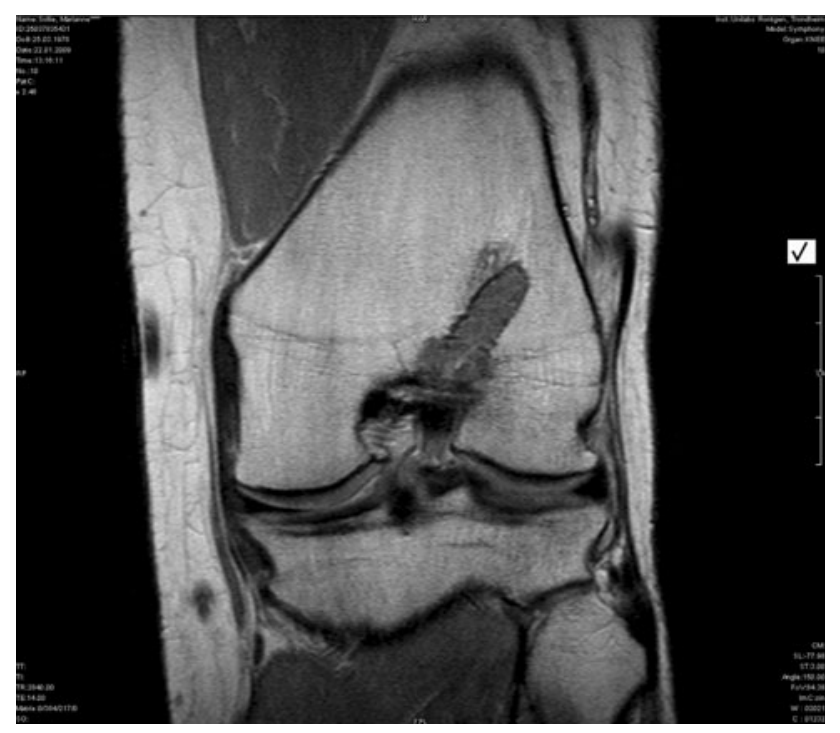

Fig. 5 An example of a not threaded residual screw tract in femur filled with material consistent with soft tissue. It is lined with a thin rim interpreted as sclerotic bone
MRI of the patients in the present study at 2 years showed a mean reduction in screw volume of $63 \%$ for the tibia screws and $64 \%$ for the femur screws [12]. At the 7 year follow-up, MRI showed no remaining bioabsorbable interference screws. Barber et al. [5] also found no screws apparent on computer tomography (CT) 7 years postoperatively.

Bony replacement of the absorbed screws would make revision surgery easier. Subtle lamellar bony elements are most often difficult to detect with MRI, and can occur even if it is not recognized with the MRI imaging sequences chosen in our study. CT is more sensitive in this respect and for delineating the sclerotic rim [42]. The findings in the present study, however, are in accordance with other studies showing that bony replacement of the screw does not always occur in humans [7, 12, 42, 43]. This is a concern for revision surgery.

In the present study, a hypointense rim lining most of the screw site was found. This is compatible with sclerotic bone, confirmed by the radiographic and CT findings of Barber et al. [7]. A sclerotic cortical lining makes later bony replacement unlikely [42]. Theoretical studies and animal experiments indicate better bony integration when adding osteoconductive substances. Composite interference screws have recently been introduced to enhance bony integration, and studies show significantly better results compared to pure PLLA-screws [6, 23].

At the 7 years follow-up, we found a residual screw tract on MRI next to the bone plug. The tract in tibia differed from the corresponding tract in femur. The tibial tract looked threaded in most of the patients, lined with the rim of sclerotic bone and filled with an amorphous soft tissue material. This is consistent with the study presented by Barber et al. [7]. The tibial tract resembled a screw surface, like a "screw-ghost", but the appearance was more indistinct than of an intact screw and the threads differed in size and thickness. This difference in size and thickness may be due to imaging shift artifacts. The mean volume of these "screw-ghost" was estimated to $406 \mathrm{~mm}^{2}$ which was larger than the estimated mean volume of the tibial screws at 2 years postoperatively $\left(403 \mathrm{~mm}^{2}\right)$ [12]. In six of the patients the volume was significantly larger. Such threaded tracts were not found in the femur where the tracts appeared more diffuse and indistinct with a thinner rim. The difference between the tract appearance in tibia and femur was obvious in almost all the patients. Possible explanations for this could be that the femur screw is positioned closer to the joint line and closer to cortical bone than the tibia screw. This may have consequence for the supply of water, blood and enzymes which are theorized to effect hydrolysis [41].

In studies on bioabsorbable interference screws the presence of screw threads is often used to determine if the 
screw has degraded [39]. Morgan et al., however, found that a PLLA interference screw revealed clearly delineated on MRI after 30 months in vivo actually was undergoing degradation. The explants were seen to be composed of screw remnants, fibrous connective tissue, cortical-like bone and cancellous bone [30]. Similarly, Park and Tibone [32] presented a case study with a late inflammatory reaction 4 years after ACL surgery. MRI clearly showed the persistence of a tibial PLA interference screw, but under the irrigation and debridement they could not find any screw or PLA remnants, and the screw observed on preoperative MRI was interpreted as a false screw-a revealed persistent screw that is actually not there.

In our study the so-called screw-ghost could in some patients be misinterpreted as persistent screws which could have a consequence when planning revision surgery after primary ACL-reconstruction.

Drogset et al. [12] observed osteolysis around the screw in three patients $(16 \%)$ in the femur and none in the tibia at the 2 year follow-up. The bone block integration was considered good in 17 patients and fair in 10 patients. At the 7 years follow-up, no osteolysis in any of the 16 patients was detected, and integration of all the bone blocks was considered good. Studies show that the rate of osteolytic changes after ACL surgery with PLLA bioabsorbable screws is low, and that the incorporation of bone blocks is considered satisfactory compared to metal screws $[8,9,19,27]$. Studies on other bioabsorbable fixation materials also show promising results regarding osteolysis and osseous incorporation of bone blocks [10, 23, 25, 33].

Tunnel enlargement may be a potential problem after primary ACL-reconstructions and revision surgery [39, 45]. In the present study, no tunnel widening was found. The reason for inconclusive findings in the literature regarding tunnel widening is unknown. BPTB-grafts result in less tunnel widening than hamstring grafts [36]. Similarly, Barber et al. [8] did not find any difference in tunnel widening between PLLA-screws and metal interference screws.

The majority of reports on bioabsorbable- and metal screws have shown comparable results in terms of stability, functional and clinical outcome [7, 9, 16, 18, 19, 24, 25, 35, 40]. The present study did not show any statistically significant differences between the groups concerning subjective knee function, KOOS score, Lysholm score, Tegner score, Lachman test or assessment of swelling.

In the authors' opinion, however, the potential advantages of using PLLA-screws compared to metal screws are not sufficient to warrant the routine use of PLLA-screws in ACL-reconstructions.

The limitation of this study is the relatively small number of patients in each group.

\section{Conclusion}

The clinical and functional results are satisfactory with no major difference between the groups. MRI at 7 years showed that the bioabsorbable screws were absorbed; however, they were not replaced by bone. This is a concern for revision surgery.

Acknowledgments The study was funded by the Norwegian Arthroscopy Association. Research funds were also received from the Faculty of Medicine, Norwegian University of Science and Technology, Trondheim. Both the BioScrews and the metal screws used in the study were provided free of charge from Linvatec, Norway.

Conflict of interest None of the authors have any potential conflict of interest to declare.

Open Access This article is distributed under the terms of the Creative Commons Attribution Noncommercial License which permits any noncommercial use, distribution, and reproduction in any medium, provided the original author(s) and source are credited.

\section{References}

1. Alentorn-Geli E, Myer GD, Silvers HJ et al (2009) Prevention of non-contact anterior cruciate ligament injuries in soccer players. Part 1: mechanisms of injury and underlying risk factors. Knee Surg Sports Traumatol Arthrosc 17:705-729

2. Alentorn-Geli E, Myer GD, Silvers HJ et al (2009) Prevention of non-contact anterior cruciate ligament injuries in soccer players. Part 2: a review of prevention programs aimed to modify risk factors and to reduce injury rates. Knee Surg Sports Traumatol Arthrose 17:859-879

3. Athanasiou KA, Agrawal CM, Barber FA et al (1998) Orthopaedic applications for PLA-PGA biodegradable polymers. Arthroscopy 14:726-737

4. Bach FD, Carlier RY, Elis JB et al (2002) Anterior cruciate ligament reconstruction with bioabsorbable polyglycolic acid interference screws: MR imaging follow-up. Radiology 225:541-550

5. Barber FA (2005) Poly-D, L-lactide interference screws for anterior cruciate ligament reconstruction. Arthroscopy 21:804-808

6. Barber FA, Boothby MH (2007) Bilok interference screws for anterior cruciate ligament reconstruction: clinical and radiographic outcomes. Arthroscopy 23:476-481

7. Barber FA, Dockery WD (2006) Long-term absorption of poly-Llactic acid interference screws. Arthroscopy 22:820-826

8. Barber FA, Elrod BF, McGuire DA et al (1995) Preliminary results of an absorbable interference screw. Arthroscopy 11:537-548

9. Barber FA, Elrod BF, McGuire DA et al (2000) Bioscrew fixation of patellar tendon autografts. Biomaterials 21:2623-2629

10. Benedetto KP, Fellinger M, Lim TE et al (2000) A new bioabsorbable interference screw: preliminary results of a prospective, multicenter, randomized clinical trial. Arthroscopy 16:41-48

11. Drogset JO, Grontvedt T, Jessen V et al (2006) Comparison of in vitro and in vivo complement activation by metal and bioabsorbable screws used in anterior cruciate ligament reconstruction. Arthroscopy 22:489-496

12. Drogset JO, Grontvedt T, Myhr G (2006) Magnetic resonance imaging analysis of bioabsorbable interference screws used for fixation of bone-patellar tendon-bone autografts in endoscopic reconstruction of the anterior cruciate ligament. Am J Sports Med 34:1164-1169 
13. Drogset JO, Grontvedt T, Robak OR et al (2006) A sixteen-year follow-up of three operative techniques for the treatment of acute ruptures of the anterior cruciate ligament. J Bone Joint Surg Am 88:944-952

14. Drogset JO, Grontvedt T, Tegnander A (2005) Endoscopic reconstruction of the anterior cruciate ligament using bonepatellar tendon-bone grafts fixed with bioabsorbable or metal interference screws: a prospective randomized study of the clinical outcome. Am J Sports Med 33:1160-1165

15. Drogset JO, Strand T, Uppheim G et al (2010) Autologous patellar tendon and quadrupled hamstring grafts in anterior cruciate ligament reconstruction: a prospective randomized multicenter review of different fixation methods. Knee Surg Sports Traumatol Arthrosc 18:1085-1093

16. Fink C, Benedetto KP, Hackl W et al (2000) Bioabsorbable polyglyconate interference screw fixation in anterior cruciate ligament reconstruction: a prospective computed tomographycontrolled study. Arthroscopy 16:491-498

17. Frobell RB, Roos EM, Roos HP et al (2010) A randomized trial of treatment for acute anterior cruciate ligament tears. N Engl $\mathrm{J}$ Med 4:386-388

18. Hackl W, Fink C, Benedetto KP et al (2000) Transplant fixation by anterior cruciate ligament reconstruction. Metal vs. bioabsorbable polyglyconate interference screw. A prospective randomized study of 40 patients. Unfallchirurg 103:468-474

19. Kaeding C, Farr J, Kavanaugh $\mathrm{T}$ et al (2005) A prospective randomized comparison of bioabsorbable and titanium anterior cruciate ligament interference screws. Arthroscopy 21:147-151

20. Konan S, Haddad FS (2009) A clinical review of bioabsorbable interference screws and their adverse effects in anterior cruciate ligament reconstruction surgery. Knee 16:6-13

21. Kousa P, Jarvinen TL, Kannus P et al (2001) Initial fixation strength of bioabsorbable and titanium interference screws in anterior cruciate ligament reconstruction. Biomechanical evaluation by single cycle and cyclic loading. Am J Sports Med 29:420-425

22. Lajtai G, Humer K, Aitzetmuller G et al (1999) Serial magnetic resonance imaging evaluation of a bioabsorbable interference screw and the adjacent bone. Arthroscopy 15:481-488

23. Lajtai G, Schmiedhuber G, Unger F et al (2001) Bone tunnel remodeling at the site of biodegradable interference screws used for anterior cruciate ligament reconstruction: 5-year follow-up. Arthroscopy 17:597-602

24. Laxdal G, Kartus J, Eriksson BI et al (2006) Biodegradable and metallic interference screws in anterior cruciate ligament reconstruction surgery using hamstring tendon grafts: prospective randomized study of radiographic results and clinical outcome. Am J Sports Med 34:1574-1580

25. Marti C, Imhoff AB, Bahrs C et al (1997) Metallic versus bioabsorbable interference screw for fixation of bone-patellar tendon-bone autograft in arthroscopic anterior cruciate ligament reconstruction. A preliminary report. Knee Surg Sports Traumatol Arthrosc 5:217-221

26. Mayr HO, Hube R, Bernstein A et al (2007) Beta-tricalcium phosphate plugs for press-fit fixation in ACL reconstruction: a mechanical analysis in bovine bone. Knee 14:239-244

27. McGuire DA, Barber FA, Elrod BF et al (1999) Bioabsorbable interference screws for graft fixation in anterior cruciate ligament reconstruction. Arthroscopy 15:463-473

28. Moisala AS, Jarvela T, Paakkala A et al (2008) Comparison of the bioabsorbable and metal screw fixation after ACL reconstruction with a hamstring autograft in MRI and clinical outcome: a prospective randomized study. Knee Surg Sports Traumatol Arthrosc 16:1080-1086

29. Moksnes H, Snyder-Mackler L, Risberg MA (2008) Individuals with an anterior cruciate ligament-deficient knee classified as noncopers may be candidates for nonsurgical rehabilitation. J Orthop Sports Phys Ther 38:586-595

30. Morgan CD, Gehrmann RM, Jayo MJ et al (2002) Histologic findings with a bioabsorbable anterior cruciate ligament interference screw explant after 2.5 years in vivo. Arthroscopy 18:E47

31. Myers P, Logan M, Stokes A et al (2008) Bioabsorbable versus titanium interference screws with hamstring autograft in anterior cruciate ligament reconstruction: a prospective randomized trial with 2-year follow-up. Arthroscopy 24:817-823

32. Park MC, Tibone JE (2006) False magnetic resonance imaging persistence of a biodegradable anterior cruciate ligament interference screw with chronic inflammation after 4 years in vivo. Arthroscopy 22:911 e911-914

33. Plominski J, Borcz K, Kwiatkowski K et al (2008) Fixation of patellar tendon bone graft in reconstruction of patellar ligaments. Comparison of bioabsorbable and metal interference screwsresults of treatment. Ortop Traumatol Rehabil 10:44-53

34. Radford MJ, Noakes J, Read J et al (2005) The natural history of a bioabsorbable interference screw used for anterior cruciate ligament reconstruction with a 4-strand hamstring technique. Arthroscopy 21:707-710

35. Rupp S, Krauss PW, Fritsch EW (1997) Fixation strength of a biodegradable interference screw and a press-fit technique in anterior cruciate ligament reconstruction with a BPTB graft. Arthroscopy 13:61-65

36. Samuelsson K, Andersson D, Karlsson J (2009) Treatment of anterior cruciate ligament injuries with special reference to graft type and surgical technique: an assessment of randomized controlled trials. Arthroscopy 25:1139-1174

37. Shelbourne KD, Gray T (1997) Anterior cruciate ligament reconstruction with autogenous patellar tendon graft followed by accelerated rehabilitation. A two- to nine-year followup. Am J Sports Med 25:786-795

38. Shen PH, Lien SB, Shen HC et al (2009) Comparison of different sizes of bioabsorbable interference screws for anterior cruciate ligament reconstruction using bioabsorbable bead augmentation in a porcine model. Arthroscopy 25:1101-1107

39. Singhal MC, Holzhauer M, Powell D et al (2008) MRI evaluation of the tibial tunnel/screw/tendon interface after ACL reconstruction using a bioabsorbable interference screw. Orthopedics 31:575-579

40. Stener S, Ejerhed L, Sernert N et al (2010) A long-term, prospective, randomized study comparing biodegradable and metal interference screws in anterior cruciate ligament reconstruction surgery: radiographic results and clinical outcome. Am J Sports Med 38:1598-1605

41. Sudkamp NP, Kaab MJ (2002) Biodegradable implants in soft tissue refixation: experimental evaluation, clinical experience, and future needs. Injury 33(Suppl 2):B17-24

42. Tecklenburg K, Burkart P, Hoser C et al (2006) Prospective evaluation of patellar tendon graft fixation in anterior cruciate ligament reconstruction comparing composite bioabsorbable and allograft interference screws. Arthroscopy 22:993-999

43. Tuompo P, Partio EK, Jukkala-Partio K et al (1999) Comparison of polylactide screw and expansion bolt in bioabsorbable fixation with patellar tendon bone graft for anterior cruciate ligament rupture of the knee. A preliminary study. Knee Surg Sports Traumatol Arthrosc 7:296-302

44. Warden WH, Friedman R, Teresi LM et al (1999) Magnetic resonance imaging of bioabsorbale polylactic acid interference screws during the first 2 years after anterior cruciate ligament reconstruction. Arthroscopy 15:474-480

45. Wilson TC, Kantaras A, Atay A et al (2004) Tunnel enlargement after anterior cruciate ligament surgery. Am J Sports Med $32: 543-549$ 